\title{
Drug Tourism: General Overview, Case Studies and New Perspectives in the Contemporary World
}

DOI 10.1515/ejthr-2016-0021

received 5 September, 2015; accepted 10 September, 2016

Abstract: Several are the motivations and natures of the activities undertaken by tourists, leading to the existence of different types of tourism, which, according to the World Tourism Organization, can be divided into major segments (e.g. Sun \& Beach Tourism, Ecotourism and etc.); each one with its own subcategories, as the religious tourism, experience tourism and so on. So, would it be possible to talk about drug tourism? Where, the drug itself would present a significant role as a motivation for travelling. Drug tourism could be seen as the journeys undertaken with the purpose of obtaining or using drugs, which are not available or are illegal in the tourist origin places. The purpose of this article was to provide a general discussion on the subject of drug tourism. In this task, some important examples were cited and the positive and negative impacts on the country or region of destination, the relationships between the different types of drug tourism with the major segments defined by the UNWTO, as well as new perspectives in this field were also discussed. As a case study, were presented information about cannabis tourism in Amsterdam, Netherlands (derived from literature searches and questionnaires in field research). This is a topic discussed only superficially but which is an obvious reality in various tourist destinations. Therefore, it is essential the development of a deeper treatment (deprived of prejudices) about the changes occurring in the contemporary world (concerning the drug politics), which may open new frontiers for this type of tourism.

\footnotetext{
*Corresponding author: Thiago Ferreira Pinheiro Dias Pereira, Department of Tourism of the State University of Rio de Janeiro (DTUR - UERJ), Av. Lúcio Meira, 233. Várzea, Teresópolis (RJ) - Brasil, Tel: 55 2136415381, E-mail: thp21@hotmail.com Leonardo Batista de Paula, Department of Tourism of the State University of Rio de Janeiro (DTUR - UERJ), Av. Lúcio Meira, 233. Várzea, Teresópolis (RJ) - Brasil
}

Keywords: Drug Tourism; Drug Politics; Cannabis Tourism; Touristic Segments

\section{Introduction}

The movements across the geographical space have always been a reality in human history. But in principle, it is only after the period associated with the "Industrial Revolution", with its significant changes in labor relations, with intensive development in means of transport and communication (the time category surpassing the space category) and with its consequent changes in social behavior, that we can talk about "Tourism", that might be considered as one of the activities that most generates currencies in the contemporary world.

Several are the motivations and natures of the activities undertaken by tourists, leading to the existence of different types of tourism, which, according to the World Tourism Organization - UNWTO (2001), can be divided into major segments (e.g. Sun \& Beach Tourism, Ecotourism and etc.); each one with its own subcategories, as the religious tourism, experience tourism and so on. So, would it be possible to talk about drug tourism? Where, the drug itself would present a significant role as a motivation for travelling. In this sense, drug tourism (or narco tourism) could be seen as the journeys undertaken with the purpose of obtaining or using drugs, which are not available or are illegal in the tourist origin places.

Drug tourism can also be defined as the phenomenon by which one's travel experience involves the consumption and use of drugs that are illegal or illegitimate both in visited destination, or in the country of origin of tourists. This would include cross a national border for obtaining medications that are not sold on your own, or travel to another country in order to obtain or use drugs that are illegal in their own country, or even travel from one province / municipality / state to another in order to buy alcohol or tobacco more easily (URIELY \& BELHASSEN, 2005). 
The purpose of this article was to provide a general discussion on the subject of drug tourism. In this task, some important examples were cited and the positive and negative impacts on the country or region of destination, the relationships between the different types of drug tourism with the major segments defined by the UNWTO, as well as new perspectives in this field were also discussed. As a case study, were presented information about cannabis tourism in Amsterdam, Netherlands (derived from literature searches and questionnaires in field research).

This is a topic still discussed only superficially, but which is an obvious reality in various tourist destinations. Therefore, it is essential to develop a deeper treatment (deprived of prejudices) about the changes (concerning the drug politics) that are occurring in the contemporary world, which may open new frontiers for this type of tourism.

\section{General Overview on Drug Tourism}

In addressing this topic, to avoid possible miscommunication, initially it might be necessary presenting some basic definitions as the concept of drugs itself, the most common drugs classifications, as well as the idea of responsible drug use.

To support these basic definitions presented here, it was used the book called "Almanaque das Drogas" (Drug Almanac), written by Tarso Araujo (2014), which became an important reference in the context of the discussion about drugs in the Brazilian scene. Thus, in general, broader definitions (provided by pharmacologists) would consider drug as any substance capable of altering the normal functioning of an organism, a concept very close to the one adopted in Ancient Greece, where the word Pharmakon could be used both to medicines and to poisons, meaning that no substance would be good or bad in itself, the use made of them is what would determine its consequences. In this approach, cannabis and cocaine would be classified as drugs, as well as aspirin and caffeine. A more formal definition established by the World Health Organization (WHO), in its Alcohol and Drug Glossary, interprets drugs as substances that affect the mind and mental processes. According to common sense, in most of times, individuals would understand that drugs might be any substance that makes you "get high", and, in this case, they are usually referring to the so called psychotropic or psychoactive drugs. Because of the fact that over the time this term has been increasingly associated only with illicit substances, usually, legal substances, such as alcohol and caffeine, are not seen as drugs. This is a mistaken view, but it gained strength, mainly from the UN treaties of 1961 and 1971 which aimed to control and / or prohibit the production and distribution of various substances. Even with the treaty of 1971 being titled as "Convention on Psychotropic Substances", alcohol, tobacco and caffeine were not even mentioned. Thus, stigma and prejudice generated in relation to illegal substances were also gradually being influenced by questions of cultural and moral values, and in some cases, the term has come even to be considered as a synonym for "bad thing or without value "; of "something of little use, or whose application is unknown"; of a "thing without quality"; of "having bad success" and even; of "prostitution", as it can be seen in the definition presented by an important dictionary of the Portuguese language (WWW. DICIONARIODOAURELIO.COM, 2015).

Still based on the information provided by Araujo (2014), the term "narcotic" (from the narkotikos in Greek - meaning "what falls asleep"), mainly from the 14th Century, was widely used by doctors to refer only the so-called "opioids", substances known for their ability to anesthetize. At the beginning of the 20th Century, with the emergence of the first national and international laws related to drug control, efforts were precisely directed to restrain and regulate the use of these substances and, therefore, the narcotic term (as well as its synonym "doping") is now used to refer to any prohibited substance; even the cocaine, a drug known for its stimulating effects (which is not an opioid, therefore not having the same effect on users), was classified by this term. This misconception occurs not only in the common sense and as an example we can quote the title of the first UN treaty on psychotropic drugs (1961), referred to as "Single Convention on Narcotic Drugs."

Nowadays, especially in the Spanish language, the term "narco" also came to be often used to refer to drug dealers. In this context, it is important to note that the definition of drugs adopted in this work refers to psychoactive drugs, that is, those who are able to change the behavior and / or the perception of users, regardless of the legal status of these substances (ARAUJO, 2014).

The numerous terminologies developed for classifying drugs might vary according to different factors, and are often subjective. Regarding the origin of these substances, the most common ratings are: Natural, Synthetic and Semi-synthetic. Regarding the effects generated in users, drugs could be: Stimulants, Depressants and Disturbing. As for the legal issues we have: Legal, Illicit and Controlled. 
Concerning the usage, the most common classifications are: Medicinal Use, Recreational and Religious. Finally, there would still be a classification that seeks to differentiate Soft Drugs and Hard Drugs, which is based on the damage caused by these substances to the health of users. But it is worth noting that even being widely used by the media and the authorities, because of its lack of scientific basis and its high dose of subjectivity (no drug would be soft or hard itself, everything would depend on how it is used), perhaps this would be the most problematic classification, not being adopted by any international organization that addresses these issues. The Netherlands would be the only country where those terms are adopted in its legislation about drugs, therefore, seeking to develop a pragmatic policy of harm reduction, with specific treatments for users of different drugs and with the separation of the markets of these substances, they tried to differentiate drugs such as cannabis and hashish (soft drugs) of drugs such as cocaine and heroin (hard drugs). Despite repeatedly used as synonyms by the common sense, terms such as User, Dependent and Addict also feature distinctions. Thus, regardless of the frequency that an individual uses drugs, this does not mean that he would be a drug addict and this is related to the fact that each user reacts differently to the effects and risks associated with the use of these substances (ARAUJO, 2014).

Thus, it would be possible to interpret the recreational drug use as the consumption of drugs by people who are seeking to live or enhance a recreational experience, and the drugs most commonly used in this case would be the alcohol, the nicotine, the caffeine, and the psychotropic substances. In this sense, the responsible drug use concept would be underpinned by the idea that an individual could consume drugs with a reduced risk of affecting his daily life, as well as the lives of others, thus the responsible use might only turn into an abusive use from the moment that it starts to interfere negatively in the user's life.

The international policy based on the war on drugs adopted by the UN and highly advocated by the United States in its actions related to its foreign policy contributed to a situation where drug tourism turned out to be only slightly encouraged, rarely discussed, and in many cases seen as a criminal attitude. In this way, it is clear that this type of tourism has many legal implications and involves big risks for these tourists, as possible penalties in the visited destination, as well as in their home countries (especially when there is an attempt to bring drugs in return, rather than only use during the trip).

Despite being a topic discussed only superficially in the researches in the tourism field, it is essential to highlight some relevant work already undertaken in this area. In this sense, according to Hoffmann (2014), usually, the term drug tourism refers to travelling aiming on legal acquisition and consumption of psychoactive substances, or a travel in which the principal objective is to use drugs. Accordingly, it would be possible to identify two main tourist's roles in society: the institutionalized and the noninstitutionalized. In institutionalized roles, the behavior of tourists in general is supported by formal travel institutions (e.g.: travel agencies, tour operators, hotel chains, transport companies, etc.), while the noninstitutionalized roles (in which generally drug tourists are included), in turn, are open and undefined (without the effective presence and use of travel agencies) in which the tourists (almost always individual) organize their own trips, do not travel in large groups and try to escape the most from destinations and activities related to mass tourism. According to this author, a possible relevant question that arises in this context would be: Drug use is the main goal for the realization of the trips, or it appears as an additional factor? Based on his results, he points out that, despite of having a real knowledge about the availability and access to drugs at their destinations, for most tourists interviewed in his research, the drug use was not the main objective, and it would only be a complementary factor. Therefore, concluded that the drug experiences are not homogeneous and might be associated with a hedonistic behavior and the search for fun, as well as the need for having deeper experiences.

Based on interviews and observations at selected drug tourism destinations (addressing questions concerning the voluntary risk-taking by drug tourists), Natan Uriely and Yaniv Belhassen (2006) developed a study in order to examine the drug use during holiday trips, exploring thus risk perceptions, as well as the associated behavior patterns. Their results illustrated that, in most cases, these tourists were fully aware of the legal, medical and social risk aspects, that they usually took precautions to reduce these risks and also that they perceived the drug use as less dangerous while traveling than in their daily routines in their home countries.

In another study, by using a phenomenological perspective and based on additional ethnographic interviews and data collected at various drug tourism destinations, these same authors investigated the nature of tourist experiences related to drugs. From empirical analysis, they realized that tourist experiences related to drug would be heterogeneous in nature and that it would involve both the search for a mere pleasure as well as for deeper experiences; in this case, these experiences would be an intensified extension of the pleasure routines of these tourists; 
they also concluded that the use of drugs during the trips would not necessarily be an escape form the daily routines and that the search for distinguished tourist experiences (by using drugs) could be linked to idea of tourists trying to get involved with more authentic aspects of local cultures or with the subcultures related to drugs (URIELY \& BELHASSEN, 2005).

Based on the results obtained in the study entitled "Drug tourism: going on a trip holiday", Andrea Grobe and Julia Lüer (2011) showed that there are tourists who travel on vacation with the intention to obtain and use drugs, but that certain risks involved should be addressed in this tourist niche market. Also highlighted some important challenges relevant to drug tourism, both for suppliers (such as travel agencies and tour operators), as for tourists itself. For suppliers, we would have risks such as: legal aspects (in most countries the sale, production and consumption of drugs are illegal); governments (in destination countries) usually adopt actions against drug tourism (by associating this practice to the crimes and social problems); and the target market in drug tourism is not as significant if compared to other tourist segments. For tourists, the problems would be related to the difficulty of finding drug tourism destinations, as there are no official advertisements and marketing; the risks involved and the legal penalties (at the country of origin as well as at the destination) and; factors associated with health risks and deaths by overdose. Therefore, they concluded that these points would negatively influence the development of this type of tourism and that, as consumers would be motivated by different issues, noticing and dealing with the risks in different ways, there would not be a typical profile of drug tourists which could be described.

Michael Winkelman (2005), in a research regarding the use of the substance Ayahuasca (a traditional spiritual medicine), in the Amazon, discussed whether these tourists should be characterized as "drug tourists" or as people who seek spiritual and therapeutic opportunities.

Yaniv Belhassen, Carla Almeida Santos and Nathan Uriely (2007), addressed issues related to a research on the social forces that motivate tourists to consume cannabis during holiday trips, as well as theoretical and epistemological issues that permeate the relationship between cannabis use, tourism and everyday life. As a result, they highlighted that cannabis use in tourism is directed and influenced by a broader process of normalization of the consumption of this drug in Western societies.
According to Hoffmann (2014), drug tourism (or narco tourism) have been initiated in the second half of the 1960s by the Americans and Europeans belonging to the counterculture movements, specifically the hippie movement and, that over the years, it underwent many changes, mainly related to the expansion of drug supplies, the adaptation of issues related to drug tourists' needs and the emergence of new destinations, but that, despite these changes, the initial proposal would have always been kept, where destinations most popular would include countries in Southeast Asia, South America, and some European countries.

In this context, numerous examples of drug tourism destinations could be cited where perhaps some of the most significant would be cases such as the mountainous region of Morocco (Rif), in Africa, where tourists, mostly Europeans, seek the producing areas of hashish for the personal use or for bringing the drug for selling at their origin countries. In Europe we could highlight famous destinations as the city of Christiania, in Denmark, with its "Cannabis free market"; the city of Prague, in the Czech Republic, which allows citizens to have, for personal use, up to 1.5 grams of heroin, one gram of cocaine, 15 grams of marijuana, a maximum of four tablets of ecstasy and LSD and 5 to 40 hallucinogenic mushrooms; Ibiza, in Spain, known for its famous night clubs and by the ease of obtaining and using drugs; Island, which has become an important destination for the use of stimulant drugs (HOFFMANN, 2014); Lisbon, in Portugal, for its decriminalization policy for drug use Magic Mushroom stores, in which it's possible to buy sexual stimulants and "legal drugs" (substances that mimic the effects of illegal drugs); and the most famous and known drug tourism destination consisting of Dutch coffee shops (establishments where the sale and consumption of cannabis and hashish are tolerated and regulated).

In Australia, we find the famous destination known as Nimbin, where there is a tolerance for the commerce and usage of cannabis. In South America, the most visited drug tourism destinations would be La Paz, in Bolivia, with its famous bar "Route 36", where it's possible to use cocaine; Bogota, in Colombia also based on the consumption of cocaine of high quality; The region of Amazon, in Brazil, with tourists searching for Ayahuasca and also the "Santo Daime Cults") and; Peru, with the hallucinogenic cactus known as "San Pedro" (used in rituals performed by some local traditional communities).

In Asia, the region of Goa, with its electronic music festivals, where several people consume synthetic drugs, and also the region of Malana, with its famous hashish production, in India; and Thailand, offering numerous 
drugs (mushrooms, marijuana, methamphetamine and opium) (HOFFMANN, 2014).

In Central America, we see a heavy flow of young Americans traveling to Mexico in search of hallucinogenic drugs and cannabis; besides the so-called "Ganja Tours" in Jamaica which although illegal, take tourists to the cannabis plantations (THE GUARDIAN, 2013). And in North America, with its recent changes in drug policy in several states, we note the emergence of new destinations as in the case of Colorado, with its Drug Tourism Campsite known as "CannaCamp", the first cannabis resort in the world (MCANALLY, 2015); plus destinations already traditionally known as in the state of California (one of the first to allow the use of medical cannabis, and where it is relatively easy for any tourist to get a prescription, that provides access to legal establishments that sell this drug).

With current changes in as regards to consumption patterns and popularity of certain substances, even the "drug culture" is being transformed (HOFFMANN, 2014). In this sense, we can expect the emergence of numerous new drug tourism destinations in various parts of the world.

\section{Positive and Negative Impacts of Drug Tourism on the Country or Region of Destination}

Broadly, tourism can have an impact, both positive and negative for the country or region of destination. With regard to benefits, can boost local economies, improve existing services, or stimulate the emergence of new ones according to the demand (e.g. internet, lodging, food, transportation, health services, etc.). But, associated with these changes, negative points can also arise for local populations, such as the loss of their cultural traits and traditions, the increase in cost of living, the removal of communities residing in areas with high potential and tourist appeal, the permanence of generated income only on the higher circuits of the economy (keeping the population poverty) and etc.

Specifically, in the context of drug tourism, in relation to the positive aspects, it is possible to occur an increase in the generation of foreign exchange and of positions in the labor market (in various sectors of the local economy), as well as an increased demand by visitors from different locations. As negative points, it could intensify crime rates (associated with the illegal commerce of illicit substances), lead to the introduction of new drugs (which would not exist before in these locations), stimulate an increased use of these substances by the "locals" (allowing the emergence of a greater amount of cases of dependence and addiction), generate disturbances and disorders caused by tourists under the influence of drugs and, in some cases, even increase prostitution indexes (activity that often, and not always correctly, turns out to be associated with this type of tourism) (WWW.ALCOHOLREHAB. COM, 2014).

\section{The Relationships between the Different Types of Drug Tourism with the Major Segments Defined by the UNWTO}

These travels, here referred to as "drug tourism", could in many cases be classified within the tourist segments defined by the UNWTO (2001). As examples it would be possible to highlight the journeys made by the so-called "drug mules" in the international drug trafficking (people who transport drugs to other countries) which might be seen as a "business tourism" (even if it is illegal); the search for cannabis use in Dutch coffee shops, that could be related to the "experience tourism"; the use of Ayahuasca in the Amazon region, which would also be seen as an "experience tourism" (in the specific case of "Santo Daime Cults" - based on the use of this substance could be associated to the "religious tourism" or "cultural tourism"); the travels for participation in international conferences on medical marijuana and other drugs, what would be a type of "Event Tourism" and etc. But it is clear that in all these examples, the main motivating factor for the travels continues to be associated with drugs.

\section{Case Study: Drug Tourism in Amsterdam, Netherlands}

With the previously discussed information, the intention was to provide some theoretical and conceptual necessary basis for a greater understanding and deepening of this theme, however, seeking to illustrate the actual existence of drug tourism in a more evident way, it might be necessary to present, even if briefly, some data and results of a case study developed by the present author, which was titled as "Turismo de Drogas na Holanda: O Caso 
de Amsterdam" ("Drug Tourism in the Netherlands: the Amsterdam case”) (PEREIRA, 2014).

Within the drug tourism, perhaps the most famous case is related to the Dutch coffee shops (establishments where the sale and consumption of cannabis and hashish are tolerated and regulated). According to data of a report of the Department of Research and Statistics of Amsterdam (2007), of the 4.5 million tourists spending a night on the town, $26 \%$ visit at least one coffee shop and $10 \%$ of tourists would even mention that this was one of the main reasons for visiting the city.

This survey aimed to address precisely the Dutch case, more specifically the scene of the city of Amsterdam, and was motivated by the creation of a law (in 2012) that would restrict the entry of tourists in coffee shops across the Netherlands, from January 2013, but that in fact turned out in effect only in some cities of the country's border.

In this sense, seeking to observe the perception of local residents and also of tourists regarding this change in legislation, as well as its possible consequences, two field works in the city of Amsterdam have been developed, generating therefore a qualitative research through the application of questionnaires to the coffee shops owners, to locals (users and non-users) and tourists (users and non-users), in which the first stage occurred in October 2012, just before the moment when the Law would be applied throughout the Netherlands, and the second in November 2013, after the law was not applied in several cities as in the case of Amsterdam.

\section{A Brief Summary of the History of Dutch Coffee Shops}

In the early 1970s, the Dutch government has developed some studies on drugs, in which the Baan report (1972) and the Cohen report (1975) ended up proposing the legalization of cannabis, however, due to existing international treaties and the views of others European countries at that time, the Dutch government considered it wiser not to undertake such action. In 1978, legislation was then amended to differentiate soft drugs from hard drugs (the idea was to separate the cannabis market from other drugs such as cocaine and heroin, as well as stimulating the development of a harm reduction policy ), thus, possession and sale of small amounts of marijuana and hashish began to be treated in a milder form (i.e., these drugs began to be tolerated, but there was no process of legalization), a fact which enabled the commerce of such substances in specific places so-called coffee shops. It is worth noting that such attitude, developed by the Dutch government, was based on an essentially pragmatic approach, it means that it was not politically or ideologically driven, and that although tolerated, sale and consumption of soft drugs, and even the coffee shops remain illegal.

The licenses for the operation of these establishments were given in the 1970s and 1980s. Today, it is no longer possible to open a new coffee shop, only being allowed to transfer licenses from one operator to another, even then, in some cases; this action may be prohibited by the government. For its operation, such coffee shops should follow the following general rules: they are prevented from making any kind of propaganda; they have a limited amount of transactions (only five grams per consumer, and should have no more than 500g in your inventory); customers can not generate disturbances in the surrounding area; the opening hours are from 8 am to $1 \mathrm{am}$; alcoholic beverages trading is not permitted, nor of hard drugs and; the sale can only be held for adults over 18 years. There is also a restriction about the location of these establishments where they should be at a minimum distance of only 250 meters from existing schools, a factor that caused the closure of several coffee shops in recent years - the total number decreased from about 850 in 1999 to 651 in 2011 (BIELEMAN et al., 2012). Failure to comply with these rules is subject to severe penalties, and inspections are intense. Importantly, the use of marijuana in public areas is not permitted, but is often tolerated in certain localities, as in some of the many parks of Amsterdam, for example.

According to information obtained from interviews with the coffee shops owners (in 2012), most of the sold hashish is imported from Morocco and Pakistan, but with regard to cannabis, we also have an expressive local production of marijuana that is known as "Nederwiet" and which is becoming increasingly popular (that according to Dutch drug policy, remains illegal). In this context, then it would be possible to note a paradox: the consumption, possession and trade of small amounts of marijuana and hashish are tolerated, but there is no regulation on the production and entry of the drug, activities that are still considered as a crime.

The coffee shop "Sarasani", in the city of Utrecht, was the first local to be allowed to sell marijuana. In the case of Amsterdam, in 1975, in the Red Light District, it was founded the "Bulldog coffee shop", considered by many as the first and most famous coffee shop in town, which ended by turning into a large network (a brand) with bar, hotel and many other units across the city, and that is usually mentioned in of many the tour guides. Annually, 
this coffee shops receives a large number of tourists, especially those who are not specifically "drug tourists" and who just want to live an experience in general prohibited in their countries of origin, thus satisfying the curiosity about these places, where you can look at the menu (Fig. 1), buy and smoke marijuana, without any legal punishment.

However, many of the "more experienced" users (respondents in this survey) have many criticisms about this coffee shop in question, both in relation to their prices, the quality of cannabis sold as well as complaints about the fact of it being always packed. As a result, they ended up opting to attend other coffee shops in general also near central tourist area but not so famous as the Green House, the Dampkrins, 4:20, the Green Place, Route 66, The Other Side, the Kadinsky, Abraxas, the Rokerij, Baba coffee shop, Amnesia, Mellow Yellow, among others.

There was also a smaller number of the visitors, who had the desire to know more deeply the local dynamics and, therefore, sought to coffee shops, which were essentially frequented by the Dutch people, (in most cases, located in remote areas and less visited, distant from around the Dam Square and the Red Light District), thus

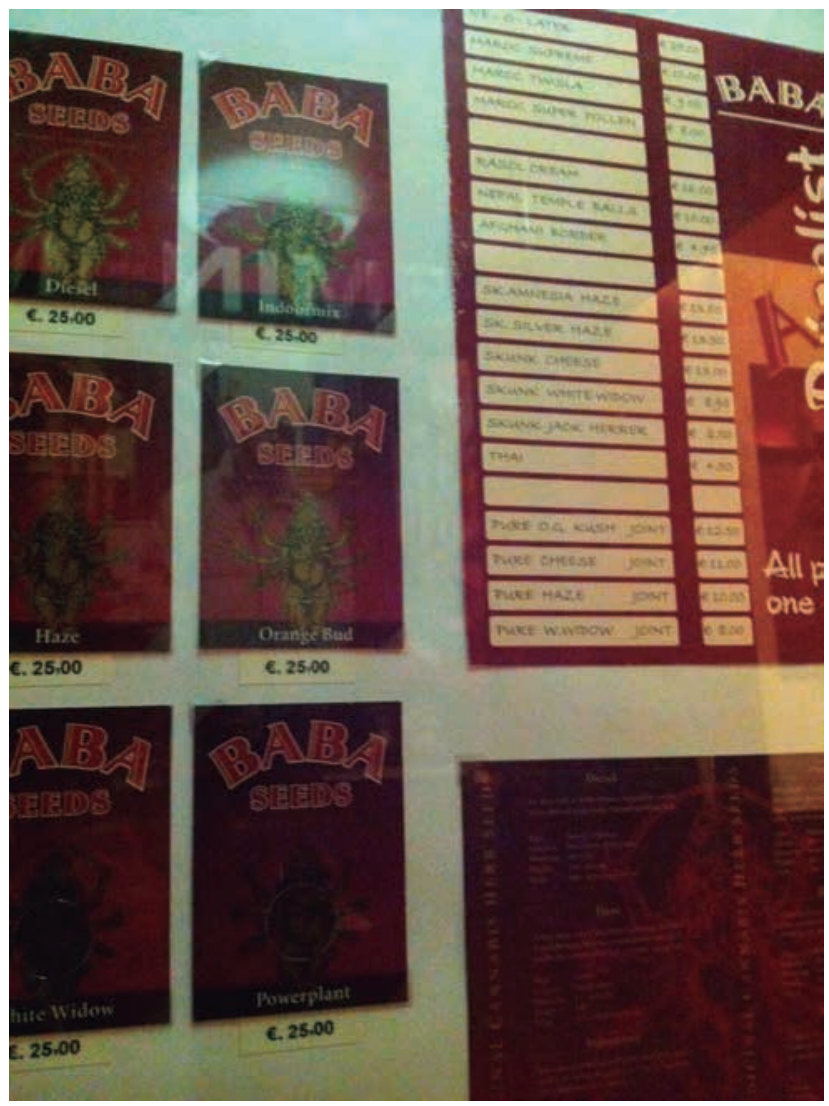

Figure 1: Cannabis and Hashish menu in a Coffe Shop in Amsterdam (Picture: Thiago Pereira, 2012). escaping the establishments full of tourists. They also said that in principle, the quality of marijuana and hashish would be much better in these coffee shops lesser known, as in Kashmir coffee shop, at Jan Pieter Heijestraat, near the Vondel Park, renowned for its quality and variety of hashish offered (where you can buy and smoke), and the Kashmir Lounge, across the street (where you can smoke and drink alcohol, but do not buy cannabis). For being frequented mostly by local consumers (recurring), there would be the need for these establishments to maintain a high quality standard of products offered (aimed at ensuring the customer and avoid claims), what would not occur in most famous and touristic coffee shops where, in general, consumers (largely "lay people") consume no more than once or twice during their stay in the city and then would return to their countries of origin.

According to the EMCDDA (2008), there are about 700 coffee shops across the Netherlands, which absorb about 3.400 employees, earning between 211 and 283 million euros annually, with each establishment selling between 208 and 308 thousand euros. Is important to remember that without the tolerance policy of the country all this money would circulate only on the illegal market, thus not allowing the collection by the State through taxes, nor the control that the government turns out to exercise in relation to the quantities and qualities of the products sold.

In addition to the coffee shops (where you can buy a huge variety of marijuana and hashish) in Amsterdam, tourists (and residents) can also find two other types of drugstores (or drugs shops): the "Seed Shops" which just sell seeds, books and artifacts to the cannabis cultivation (e.g. Sensi Seeds, Barneys Farm and Green House) (Fig. 2) and the "Smarts Shops" that sell "magic mushrooms" (the most famous being the Magic Mushrooms) (Fig. 3).

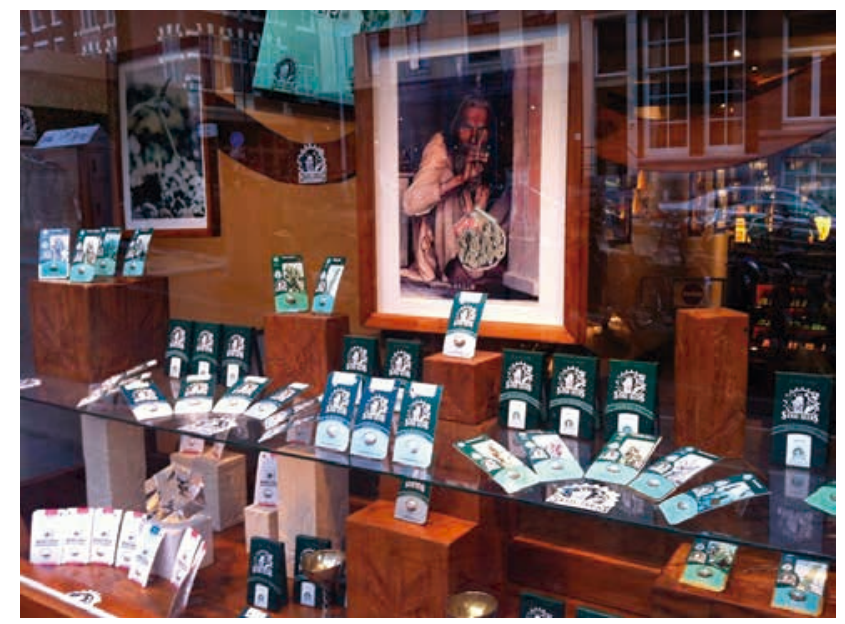

Figure 2: Seed Shop in Amsterdam (Picture: Thiago Pereira, 2012). 


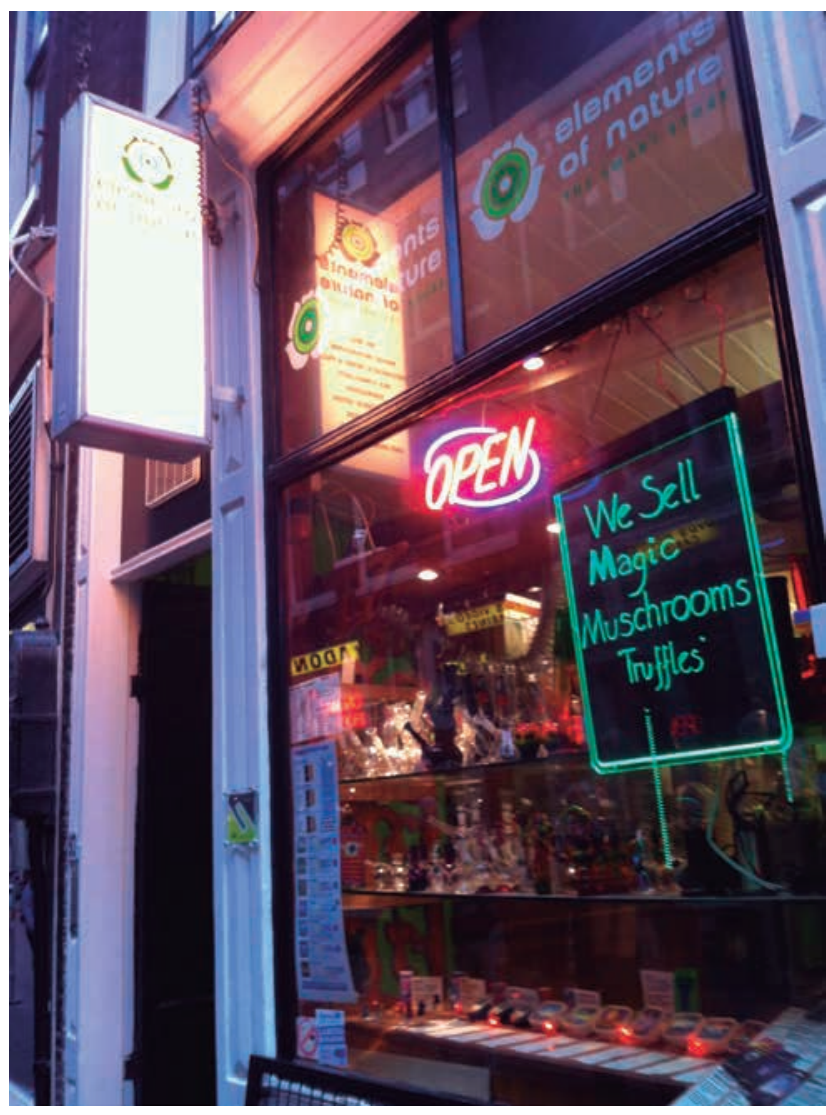

Figure 3: Smart Shop in Amsterdam (Picture: Thiago Pereira, 2012).

According to official statistics, in 2011, the tourism industry in the Netherlands generated 37.3 billion euros, employing 412.000 workers in this sector, which accounted for $4.5 \%$ of total positions in the country's labor market. In recent years, despite a small reduction associated with the global economic crisis, it is possible to state that the situation remained quite stable compared to 2011 figures (WTTC, 2013 apud Tourism industry sub-sectors - Country Report the Netherland, 2014).

Based on data provided by the Netherlands Board of Tourism and Convention (NBTC), in 2009, among the various options of activities to be carried out in the Netherlands, of total number of tourists who arrived in the country, $16 \%$ visited the coffee shops or the smart shops (Tourism industry sub-sectors - Country Report the Netherland, 2014).

In this sense, the "cannabis tourism" is evident and can be verified by several factors such as the existence of specialized tour guides on the subject (such as "Smokers Guide" - GUIDE of Coffee Shops, easily found in souvenir shops, or in coffee shops), as well as the fact that almost all the traditional tourist guides mention these establishments. There is even the offer of a "coffee shop tour", which tells the story of the coffee shops of Amsterdam, taking visitors to the main coffee shops of the city (Fig. 4).

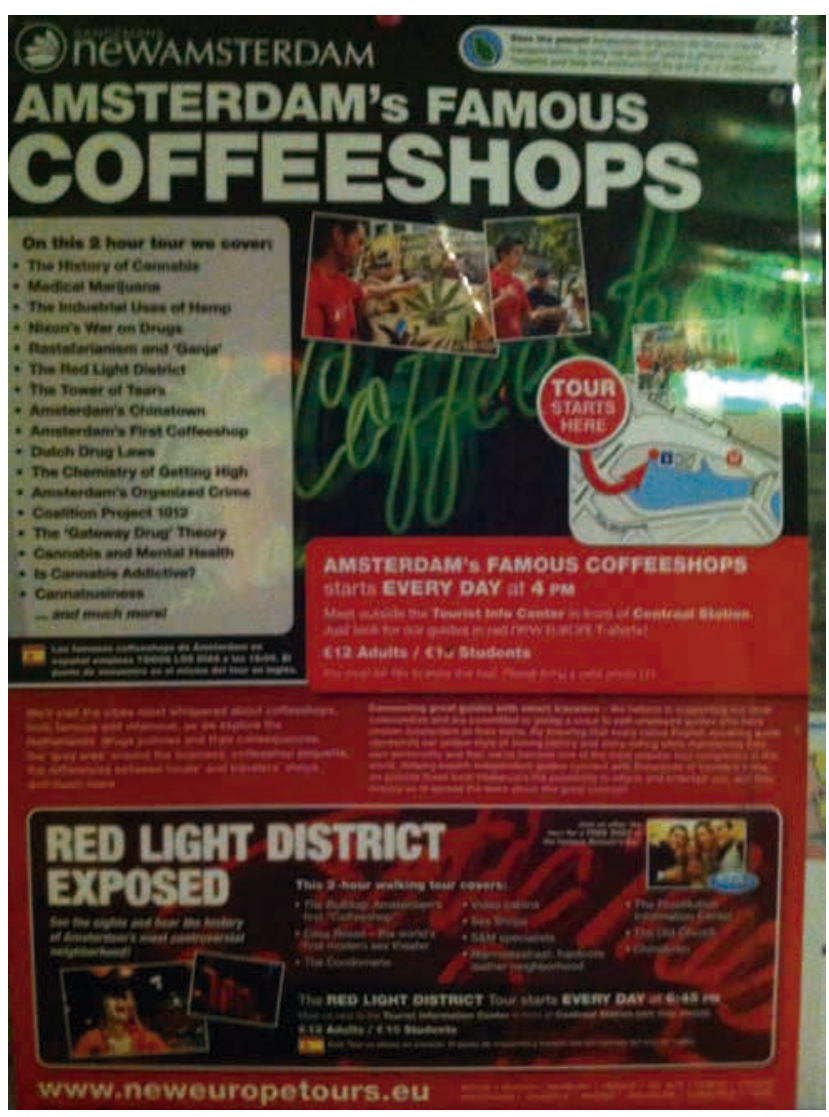

Figure 4: Coffee shop tour advertisement in Amsterdam (Picture: Thiago Pereira, 2012).

We can also highlight the existence of the "Hash, Marihuana \& Hemp Museum" (Fig. 5) and the "Hemp Gallery", located in two annex buildings in the Red Light District. Both intend to present the history and the various uses of cannabis and hashish with an extremely didactic manner, including having a greenhouse with "indoor" cannabis cultivation, so that tourists can get to know closely actual specimens of "marijuana plants" (Fig. 6). Taking into account the various UNWTO touristic segments discussed earlier, this would be a case where the drug tourism could be associated, or even classified as "cultural tourism".

In the "Cannabis College", also in the Red Light District (just a few meters away from the museum), are offered several specific courses on this topic (certified) as well as general information about the different types of uses and cultivation of cannabis. In this sense, it turns out to be a nice and cozy space for discussion and exchange of experiences, where "grass" smoking is allowed (they also have an illustrative greenhouse). For attracting tourists in order to gain knowledge by attending regular courses for a certain period would be also possible to define this situation as an "Academic Tourism". 


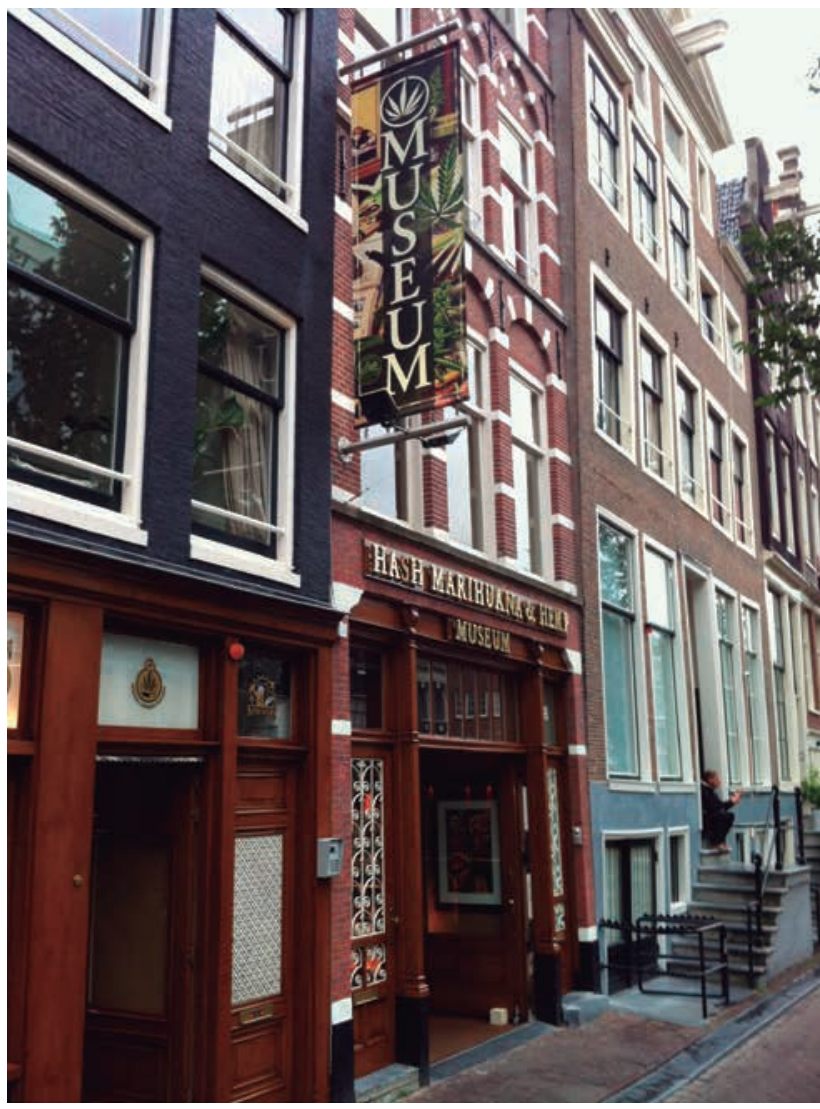

Figure 5: Hash, Marihuana \& Hemp Museum in Amsterdam (Picture: Thiago Pereira, 2012).

The famous "Cannabis Cup" (Fig. 7), also plays an important role in the "cannabis tourism" in Amsterdam. The event, which is promoted by a well-known magazine, the "High Times" (specialized in the subject), held annually in November (lasting five days), count with the awarding of the best producers of marijuana, numerous lectures on farming, recreational and medical use and public policies regarding cannabis, as well as artistic and cultural activities. Advertising carried out for disclosure is intense, and there are even several tourist agencies that offer travel packages in which are included air tickets, hotels and tour programs associated with the event. With the payment of a registration fee (around \$250), any person, from anywhere in the world, can become jurors in the competition that selects the best marijuana, which in practice means smoking all competing varieties. As it is considered one of the largest events associated with the topic, "Cannabis Cup" of Amsterdam, attracts tourists from around the world, who move to the city with the main motivating factor for the journey the desire to participate in this "marijuana cup ". As it is a large organized event (even if the subject is associated with a type of drug) we could also consider this case under the segment of "Business Tourism”.

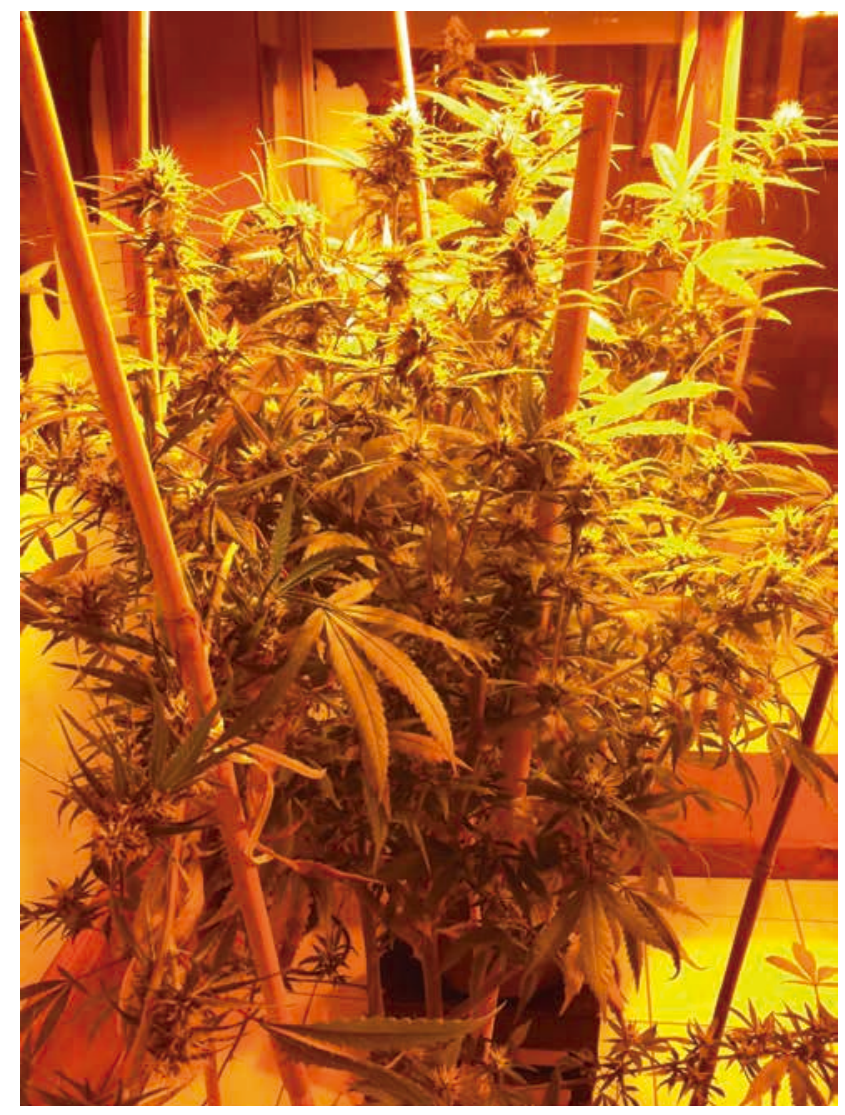

Figure 6: Indoor cannabis cultivation of the Hash, Marihuana \& Hemp Museum in Amsterdam (Picture: Thiago Pereira, 2012).
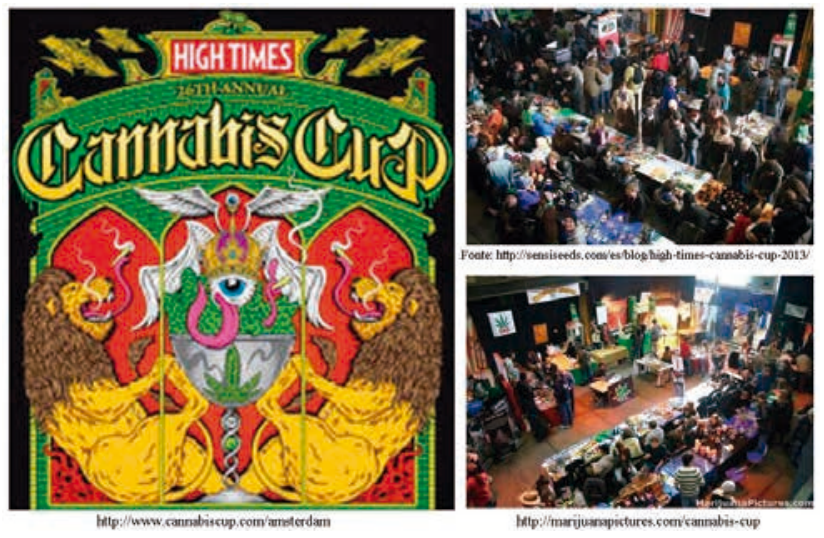

Figure 7: „Cannabis Cup“ in Amsterdam.

Drug tourism in the Netherlands, especially in Amsterdam, is a reality and enables the emergence of many obvious benefits. These specific tourists, which have as their main motivating factor for travel the search for drugs, as well as the desire to know a pragmatic and tolerant culture in relation to trade and use of them (especially cannabis), not only consume the products offered in the coffee shops thus do not spend money just buying marijuana, hashish or magic mushrooms. By observing 
the question more broadly, tourists who visit Amsterdam (or any other location) are hosted in hotels and hostels scattered throughout the city, they feed in restaurants and cafes, sit and drink in the bars, attending discos and nightclubs, sometimes seek prostitution (legalized), visit museums, rent bikes, conduct city tours and canal tours, go to pharmacies, go shopping in various souvenir shops and boutiques of different brands, use the public transport system, go to the tulips growing areas, travel to other cities of the country and etc. Therefore, end up using and encouraging the development of numerous existing services, contributing to the generation of jobs and boosting and increasing the local and national economy.

Moreover, when they return to their countries of origin, also contribute to tourism in the Netherlands telling their stories and experiences, which can act as a very effective form of advertising, attracting the interest of a large number of potential new visitors from many different profiles and not necessarily only drug tourists.

On the other hand, it is essential to reflect on the possible harms and negative points, which can also be derived from this type of tourism. Some of the criticisms presented by Dutch citizens (bothered with tourism of drugs) are associated with the disorder and uproar made by tourists (on drugs) in the surrounding areas of coffee shops, or in public areas in general; the fact that many tourists use the drug outside the allowed sites; to the odor emitted by the burning of marijuana cigarettes; and also to the perception and attitude of some visitors, who seem to believe they can do whatever they want (as prostitution and the use of soft drugs are accepted), but who do not behave the same way in their countries.

Another relevant question that somehow could be interpreted as a diplomatic issue concerning international relations consists of the divergences noted in the relationship between the Netherlands and its neighboring countries (and, more broadly, with the EU itself) which present inverse positions, not tolerating trade nor the use of soft drugs that would be seen as a crime. In this context, many citizens from several European countries cross the Dutch border in order to buy and use cannabis, thus performing the drug tourism. But the real issue arises when many of these tourists decide to transport the marijuana in the return, so as to commercialize the herb in their home countries (where it is illegal). The geographical proximity between European countries and the facility to cross its borders due to the agreements stipulated by the European Union make it an even bigger and recurring problem, intensifying the pressure on the Netherlands to change its policy of tolerance, or come up with solutions that hinder or inhibit this practice.
In this way, the Dutch government struggles to reconcile its economic issues with its international relations, because while having the profit arising from a million and a half tourists who frequent the coffee shops, also gets a lot of pressure from countries with which shares a border (e.g. Germany and Belgium), which require greater control and rigor in the sale of marijuana.

Regarding the Dutch domestic politics, it is possible to highlight the existence of four expressive political parties, where the Social Democrats of the Dutch Labour Party (PvdA) and the Democrats 66 (D66) advocate the legalization of marijuana, while the Christian Democrats (CDA) and the People's Party for Freedom and Democracy (VVD) are seeking toughen the policy of tolerance, making it more stringent, a situation that generates a major debate in the internal politics of that country.

The negative views and criticism in relation to drug tourism (defended by a portion of the conservative Dutch citizens) associated with pressure from other European countries helped strengthen the government coalition of the two parties opposed legalization. In this way, conservatives managed to pass a more restrictive law, which, in May 2012, entered into force in three southern provinces (String, Limburg and Zeeland), thereby preventing the entry, the purchase and the consumption of marijuana by tourists in the Dutch coffee shops, what would be allowed only to citizens and legal residents. In principle, the new law would be applied across the Netherlands from January 1, 2013, leading therefore to the end of "marijuana tourism" across the country.

In practice, this law turns the coffee shops in a sort of "private club" that can have a maximum 2000 members (over 18 years old), who must certify that they are Dutch citizens or legal residents. Individuals can join to only one coffee shop of their choice and it is not allowed their entry into other existing establishments, being the adhesion of each member reviewed annually. There is also the requirement of the presentation of a pass (such as a membership card or membership registration, which became known as "weed pass" or "weitpas") that must be made in both the entrance as in the exit, thus allowing the registration of how many times you attended the coffee shop.

The imminent ban on the presence of tourists in coffee shops generated a cloudy prospect for the economies of major cities that tolerate the existence of these establishments, especially in cities located near the borders of the country where the pressure for change coming from neighboring countries is stronger. The biggest concern of the mayors of these border towns lay in a real possibility of a drop in annual revenue what would influence negatively on local economies, in the offerings of several 
services (not only coffee shops) as well as in the reduction of vacancies in the labor market. For large cities, in addition to these effects on a local scale, the question can also profoundly affect the Gross Domestic Product (GDP) of the country.

The mayors of the four largest cities in the Netherlands (Amsterdam, Rotterdam, The Hague and Utrecht), where is located the majority of coffee shops, had positions contrary the mandatory application of the law, especially the mayor of Amsterdam, a town that has one-third of establishments of the country which generate numerous jobs and significant economic activity - mainly by money spent by tourists - and only shows small and few problems generated by drug tourists. Thus, although they understand that central government policy should be for the entire country, they claimed that the case of Amsterdam (and the three other major cities) was very specific mainly due to the large number of tourists who visit this city that is much higher than the figures from other areas of the country.

About seven million tourists visit Amsterdam each year, of which about a million and a half attends at least one coffee shops. In October 2012, in an interview with the newspaper "De Volkskrant", the mayor of this city, Eberhard Van der Laan, said the law would be applied, but this should be done in accordance with the affected municipalities who are supposed be free to heed it or not (WWW1.FOLHA.UOL.COM.BR/TURISMO, 2012).

Another argument against the law is the possibility of loss of control over the quantity and quality of soft drugs tolerated, on the age of consumers, as well as about the location and concentration of points of sale and consumption. The drug would continue to be sold illegally in the illicit street market, who could lead to an increase in crime rates and disturbances caused by users that would no longer be restricted to the vicinity of coffee shops, hence spreading to different areas of the cities, thus generating a bigger problem than that associated to drug tourism itself.

In a recent research conducted with Dutch judges and prosecutors, it was found that $63.9 \%$ of the respondents claimed not interpreting the requirement of proof of legal residence in the country for access to coffee shops as an efficient way to reduce or eliminate public disorder in the surrounding areas of these establishments, a view that was based on numerous reports about increasing in disorder and crime by the illegal trade in streets of the southern municipalities that adopted this form of restriction (LENSINK, et al., 2013; Apud ROLLES, 2014).

As a concrete example of these consequences, we can mention the case of the city of Maastricht, located near the borders with Belgium and Germany, where both the prohibition of tourists, as the "weed pass" were applied.
Even with all these negative facts arising from the adoption of a less tolerant attitude, repression and surveillance remain intense, indicating that the local government does not intend to go back.

\section{Results Related to the Case Study}

After completion of the questionnaires, some points are worth highlighting. Please note that the observations and views set out here are nothing more than the perception of an empirical research based on a qualitative research, thus containing a high degree of subjectivity.

The results of the interviews conducted in October 2012 showed that in relation to 130 tourists interviewed (62\% users and 38\% non-users), $83 \%$ had a negative stance toward the change in the law, and the main criticism was based on the loss of opportunity to perform an experience which would be impossible in their countries of origin. In other words they claimed that the coffee shops had big role in the existing imaginary in relation to Amsterdam (even if such tourists do not attend these establishments) and that the new law would end up with a sort of " mystique" or "glamor" in relation to the city that have been developed by visitors over time; $14 \%$ had a favorable speech about the new law, claiming, in most cases, that no drug should be tolerated, consumed or marketed anywhere in the world - this group demonstrated a clear support for the "war on drugs" policy ; and 03\% were indifferent on the issue. It is worth noting that among the tourists surveyed $79 \%$ had already visited a coffee shop, or showed interest in visiting these establishments in the period they were in town.

As for the 130 residents surveyed, 38\% claimed to be frequent users, $13 \%$ occasional users and $49 \%$ did not use the drug. The widely held position was negative in relation to the new law (89\%) and even non-users, in general, were against its implementation in the city of Amsterdam. The main justification used to support this view consisted of the potential income losses in various sectors of the economy, especially in services. Only $08 \%$ was in favor of the law and 03\% was indifferent.

One point that should be emphasized, was a strong critique presented about a growing movement of interest of the conservative wing of the government to have more control over its citizens. Many of the interviewed users showed great fear about the records of their frequency in coffee shops ("weed pass"). One reason could be a possible negative stereotype associated with marijuana users and patrons of coffee shops. But the main criticism was 
on doubt regarding the use that the state could do with the information about who frequents the coffee shops, a fact which may cause numerous problems for consumers, both in their personal lives and professional.

Even respondents who claimed not being users, shared this view, and interpreted this pursuit of greater control over the habits of citizens as a real attempt of the state to interfere in the social behavior of its individuals, which would be a major setback for the country as a whole. One respondent raised the question: "With that starts control over a segment of society (the cannabis users), but what's next"? He was afraid that his country that historically has a cultural stance grounded on respect for individual freedoms, would turn into something like the worlds exposed by George Orwell in "1984", or by Aldous Huxley in "Brave New World”.

Regarding the results associated with the owners of 32 coffee shops where questionnaires were applied, only two were in favor of the change in the law and none were indifferent. However, the geographical location of these establishments had a strong influence in the emphasis of the speech presented, as well as their arguments. Therefore, owners of coffee shops located close to the tourist areas were notoriously incisors to defend that the new law should not be applied in Amsterdam; with a greater distance these areas, the speech was softer and sometimes almost reflected certain indifference; Finally, the only two cases in favor of restricting tourists were in more distant areas from the center (Dam Square), where these owners said they received almost no tourists, and one of them even was against the presence of non-residents in his establishment.

But he most interesting fact was the possibility of identification of a much broader issue than the presence or absence of tourists in coffee shops, namely the real fear regarding the interest of the government to achieve greater control over the practices and attitudes developed by his society.

The "weed pass" ("wietpas", or "marijuana pass") should have entered into effect nationwide in 2013, but what happened was that, basically, this position was rejected and abandoned by the new coalition that came to compose the government in October 2012. As a result, municipalities continued to maintain local control over their policies towards the coffee shops, where some choose not to allow their existence, others adopted the new law (restricting access only to the Dutch and legal residents) and, especially in the case of cities that have significant role in the country's tourism, tourists continued to be accepted in coffee shops (as it happened in Amsterdam).
From the interviews carried out during the second stage of the research (in November 2013), it became clear that the possibility of change in the law across the country ended up generating a kind of touristic "BOOM" in 2012 (the supposed previous moment for national implementation of the new law). A large number of tourists interviewed claimed they already had plans to visit the country, but the news of the ban on visitors in coffee shops made them anticipate their travels; they wanted to live the experience and not just listen to the stories and reports from other tourists, who were able to buy and smoke cannabis in a coffee shop in that sense they also wanted to be able to develop their own perceptions and tell their own stories.

In this sense, all media and disclosure associated with the idea of tourists ban in coffee shops benefited greatly the economy of Amsterdam. But in 2013, the information obtained illustrated that visitation rates to such establishments returned to display numbers close to those before 2012, since there was no longer a need to "run" to seize the last opportunity to live a peculiar and unique experience associated to drugs, and without the risk of legal penalties.

Drug tourism in the Netherlands remains a reality, with obvious benefits (mainly economic) as well as relevant harms (already discussed above). Fears about the quest of the central government (mainly from the conservative wing) for greater control over the society remains, but the maintenance of the decision-making autonomy of local governments (Municipalities) contributed to the development of a perception in which individual freedoms are still respected in this country.

\section{New Perspectives Concerning Drug Tourism}

Numerous and significant are the changes in relation to drug policy adopted in different countries in the contemporary world. The vision associated with the idea of war on drugs weakens forward to concrete examples of the failure of this approach over the last 40 years, such as the fact that even with the huge investments to intensify repression, drug trafficking has not decreased, on the contrary because it is an illicit activity provides significant financial gains for those who choose to take risks in this activity. This context allows the emergence of a new and fertile field of research for those who wish to discuss drug tourism as well as the development of new destinations, where the tourist potential for the production, trade 
and use of several drugs in different locations (usually repressed by still being considered as illegal or immoral) could then be transformed into tourist product, thus satisfying the growing demands resulting from this type of tourism.

Some examples could be used to illustrate these changes. In South America, Uruguay (a nation where long ago the laws do not interpret the possession and consumption of drugs as a criminal matter), from an initiative of former President Jose Mujica, adopted a pioneering stance becoming the first country to legalize the recreational and medical use, the cultivation and the commerce of cannabis. In fact, this country has chosen even by nationalizing the production and distribution of this drug, enabling citizens and residents (registered previously) to acquire this substance in pharmacies, perform home cultivation for personal use, or participate in "cultivation clubs" (in this case can possess up to 99 cannabis plants, but there can be no commercialization) In this context, it is noteworthy that the official position of the government argues that the initiative to legalize the production and sale of marijuana was held in order to deal with drug trafficking domestic problems, and will not be allowed to sell to non-residents, therefore, in theory drug tourism will not be accept.

Despite this official government speech against this type of tourism, this situation already allows the emergence of an incipient drug tourism, mostly carried out by tourists from other countries of South America (due to geographical proximity and low cost of the trip) that even not having the possibility of purchasing cannabis legally in pharmacies, decide to travel to that destination to satisfy the desire to consume this substance without worrying about risks and legal penalties (there is ease of getting into the illegal market) and also to quench curiosity about the fact of cannabis be truly legalized in Uruguay. In this scenario, emerge numerous assumptions and questions about the future of this country, such as: Could we think about the rise of drug tourism in this area? If this occurs, Uruguay could become a major tourist destination of cannabis users in Latin America? Uruguay could become a "kind of Holland," but in a country in the southern hemisphere? What are the benefits and harms that could be generated? Anyway, this is a fact that has fundamental importance in the directions on the issue related to drug policy on a global scale as it is the first concrete experience in order to change the attitude towards drug use. If the positive points of this action become obvious, perhaps other countries will follow suit.

Changes in perception and attitude towards drugs are also taking place in other Latin American countries. Brazil has been discussing possible changes in its legislation, which are the first steps in an attempt to decriminalize the possession and personal use of drugs. Another point worth mentioning occurred in January 2015, when the National Agency of Sanitary Vigilance has removed the "Cannabidiol" (CBD) from the list of substances banned in the country, becoming classified as a controlled substance with permitted use only in specific situations (with a medical prescription). . With this measure, there is huge potential of Brazil becoming a major drug tourism destination in South America, for the fact of this substance still is banned in most surrounding countries. It is likely to start a kind of "Medical Tourism" held by visitors seeking legal ways of obtaining this drug. However, due to the resistance of the government's more conservative parties (right parties) and prejudice associated with moral and religious matters, these actions still occur very slowly.

Argentina is also going through a process of discussion on the decriminalization of drugs and the leaders of Guatemala and Costa Rica initiated a debate on the possible legalization of cocaine; Colombia also spoke in favor of this position, if other countries also support the change (THE ECONOMIST, 2012). Chile already had a tolerant legislation to the personal use and possession of small amounts of cannabis; consumption in private spaces is not punished and when it is performed in public areas is considered only as a misdemeanor (not being classified as a crime), but the cultivation for personal use was still illegal. In July 2015, this country has taken an important step toward building a more coherent policy towards marijuana when, in a first vote, the majority of deputies approved a bill that will stop penalizing growing marijuana for personal use, also allowing its use for medicinal, recreational and religious purposes.

In the United States, the intensification of discussion and debate associated with medical and / or recreational uses of cannabis, as well as its derivatives shows a strong movement of changing perception in relation to that plant, even though, overall, this process might not be driven by ideological issues, but for reasons and interests which are essentially economic. Due to the autonomy of its federal states with regard to their local legislative issues, some US states have achieved great progress on this matter, enabling that the commerce and the recreational and / or medical use became legal in some of them - especially during the years 2013 and 2014 - as in Colorado, in the state of Washington, in California (medical cannabis), in the capital, Washington DC (MACCOUN, 2011) and more recently in Alaska and in Oregon. Predictions are that during 2016, several other states also will undergo popular referendums processes to discuss the use of cannabis. 
Even so, national and international policies advocated by the US central government remain that of "war on drugs" (which turns out to function as a strategy of interference / intervention and control in various drug producing countries in Latin America like Colombia and Bolivia, where the US government acts in a direct way seeking to curb the cultivation of plants as the "coca" Erythroxylon coca - negatively affecting local traditional cultures and interfering in the decisions of the domestic policies of these countries).

In Europe, in different countries it is possible to note a less biased approach to drugs, as well as greater respect for individual freedoms and the development and adoption of harm reduction policies have become increasingly common. As examples, we could cite the case of the Netherlands (previously discussed); Portugal which somehow also had a leading role on this continent, when 12 years ago began to allow the possession of drugs for personal use, what has made this country to be known as a world reference in this theme nowadays.

More specifically with regard to cannabis, many European countries have followed a path seeking to develop more tolerant drug policy such as Spain (with their clubs to purchase and use of marijuana - Restricted to residents) and Czech Republic (drug tourism destination also previously mentioned). In the African continent, the same happened in South Africa. There are also situations where cultural and traditional practices go beyond the legal issues, as in the case of Morocco and its production of cannabis and hashish. And in Australia, although marijuana remains illegal, the possession of small amounts has already been decriminalized in many states, besides the fact that this country is passing through a process of formalizing the use of medical marijuana.

It is evident, therefore, that the first actions in favor of a broad and unrestricted decriminalization of drugs are already occurring, and these deeper changes are only a matter of time (VIEIRA, 2013).

\section{Conclusion}

The main aim of this work was to contribute to the development of deeper discussions on the subject of drug tourism, through an approach supported by theoretical and conceptual bases developed in tourism. Clearly this is a research field still unexplored and, in many cases, ends up being treated only by visions associated with common sense, being interpreted as a taboo and where moral, political and religious values; the criminalization of drugs; and prejudices speeches ended up by influencing the discussions and the development of researches in this area in a negative way.

Thus, there was an attempt to present a general discussion on the subject, in which, some basic conceptual issues needed to define and contextualize this kind of tourism were highlighted. Subsequently, based on literature surveys, efforts were directed to the presentation of a general overview on drug tourism, that is, the proposal was to demonstrate that, despite being a tourist area still little discussed, there are already some relevant researches which can be used as references for supporting future works.

It is possible to note that speech on the so-called "War on Drugs" came gradually losing strength over time, a fact that is directly associated with inefficiency of the policy advocated by the UN and endorsed intensely by the US government. Even with all this effort and investments in this "war", the results can be interpreted as a failure, for drug trafficking has never been so expressive, which is reflected in the huge varieties and quantities of transported substances, as well as in the profit generated, always being one step ahead with numerous strategies to circumvent the inspections. In this context, discussions related to this issue, in general, basically highlighted the negative aspects related to the harmful effects that drug use can cause for individuals and for societies, thus stimulating a vision where drugs would be a problem to be solved because of the health damages generated, because many are illegal, and because using them would configure a crime.

It became clear that it is possible to relate the diverse types of drug tourism with the major segments defined by the UNWTO (2001), what can help to stimulate the development of several works, debates and exchanges of experiences between researchers from distinct areas and segments inherent in studies carried out in the field of tourism by allowing different practices, visions and approaches that complement each other towards a production of ideas, reflections and proposals of wider and more comprehensive activities which might complies with existing complexity in this phenomenon.

This study set out to be both a production of conceptual theoretical nature (by presenting a broad survey of the most significant researches related to drug tourism - briefly presenting the main ideas and results obtained by these authors) and also an practical, empirical and phenomenological study, with the presentation of the results and the analyzes undertaken by that author, in a research conducted in one of the most famous and sought 
drug tourism destinations, the city of Amsterdam in the Netherlands.

Based on the information discussed throughout this work, it can be seen that drug tourism is a reality in the contemporary world, where changes in perceptions and the current transformations in relation to drug policies developed by several countries allow the emergence of a wide field of academic research, as well as numerous new possibilities for professional performance of actors involved in the development of tourism (such as travel agencies, tour operators, tour guides, etc.).

Drug tourism tends to develop widely with the emergence of new destinations, facilities and services and itineraries tailored to meet the increasing demand that arises in this new scenario, where perspective changes at the local scale can generate huge impacts and transformations in global politics based on the "war on drugs", after all, never in history there has been a society without drugs.

\section{References}

[1] Araujo, T. (2014). Almanaque das drogas (2nd ed.). LeYa: Sao Paulo, 324

[2] Belhassen, Y., Santos, C.A., \& Uriely, N. (2007). Cannabis usage in tourism: A sociological perspective. Leisure Studies, 26(3), 303-319

[3] Bieleman, B., Nijkamp, R., \& Bak, T. (2012). Coffeeshops in Nederland 2011. Available at: http://www.intraval.nl/pdf/ b108_MCN11.pdf (Accessed July 14, 2014)

[4] EMCDDA - European Monitoring Centre for Drugs and Drug Addiction, 2008 (2008). Annual report: The state of the drugs problem in Europe. Available at: http://www.emcdda.europa. eu/publications/annual-report/2008 (Accessed July 20, 2014)

[5] Grobe, A., \& Julia, L. (2011). Drug tourism: Going on a holiday 'trip'. In A. Papathanassis (ed.) The long tail of tourism: Holiday niches and their impact on mainstream tourism. Wiesbaden: Gabler, 2011, 137-147

[6] Hoffmann, B. (2014). Drug consumption tourism as a social phenomenon. Trakia Journal of Sciences, 12(4)

[7] Mcanally, L. (2015). Drug tourism, an all-new enjoyment. Available at: https://www.linkedin.com/pulse/drug-tourismall-newenjoyment-leon-mcanally (Accessed September 20, 2015)

[8] Maccoun, R.J. (2011). What can we learn from the Dutch cannabis coffeeshop system? Addiction, 106(11), 1899-1910
[9] Pereira, T.F.P.D. (2014). Turismo de drogas na Holanda: 0 caso de Amsterdam. Revista Carbono: Natureza, Ciencia e Arte, 8. Available at: http://revistacarbono.com/artigos/08turismodedrogas-thiagopereira/ (Acessed July 20, 2015)

[10] Rolles S., Murkin G., Kushlick D., Blickman T., Zwitser G., Barra, A., \& Sanchez L. (2014). Cannabis policy in the Netherlands: Moving forwards not backwards. Available at: www.tdpf.org.uk (Accessed July 15, 2014)

[11] Department of Research and Statistics of Amsterdam (2007). Yearbook 2007. Available at: http://www.iamsterdam. com/en-GB/business/hotel-development/statistics-andpublications (Accessed July, 13, 2014)

[12] The Economist (2012). Uruguayan drug legalization - thinking the unthinkable: A bold, if fuzzy, proposal. Available at: http:// www.economist.com/node/21557804 (Accessed July 20, 2015)

[13] The Guardian (2013). Jamaica's Ganja Tours draw the tourists. Available at: http://www.theguardian.com/world/2013/ sep/09/jamaicaganjatoursdrawtourists (Accessed March 17, 2015)

[14] Tourism Industry Sub-Sectors (2014). Country report the Netherland. Available at: http://ec.europa.eu/enterprise/ sectors/tourism/tourism-businessportal/documents/ business/internationalisation/the_netherlands_country_ report.pdf (Accessed July 20, 2014)

[15] UNWTO - World Tourism Organization (2001). Organizacao Mundial Do Turismo. Introducao Ao Turismo. Traduzido por. Dolores Martin Rodriguez Corner. Sao Paulo: Roca

[16] Uriely, N., \& Belhassen, Y. (2005). Drugs and tourists' experiences. Journal of Travel Research, 43(3), 238-246

[17] Uriely, N., \& Belhassen, Y. (2006). Drugs and risk-taking in tourism. Annals of Tourism Research, 33(2), 339-359

[18] Vieira, W. (2013). E hora de pensar diferente: A repressao military consumiu dinheiro e gerou violencia sem conter a expansao do poder do narcotrafico. Available at: http:// www.cartacapital.com.br/sociedade/e-hora-de-pensardiferente-1489.html (Accessed September, 05, 2015)

[19] Winkelman, M. (2005). Drug tourism or spiritual healing? Ayahuasca seekers in Amazonia. Journal of Psychoactive Drugs, 37(2), Special Issue: Ayahuasca Use in Cross-Cultural Perspective, 209-218

[20] WWW1.FOLHA.UOL.COM.BR/TURISMO (2012). Turistas Terao Acesso aos Coffee Shops de Amsterda Diz Prefeito da Cidade. Available at: http://www1.folha.uol.com.br/ turismo/1179057-turistas-terao-acesso-aos-coffee-shopsdeamsterda-diz-prefeito-da-cidade.shtml (Accessed July 20, 2014)

[21] WWW.ALCOHOLREHAB.COM (2014). Drug tourism. Available at: http://alcoholrehab.com/drug-addiction/drug-tourism/ (Accessed July 15, 2014)

[22] WWW.DICIONARIODOAURELIO.COM (2015). (Accessed July 12, 2015) 